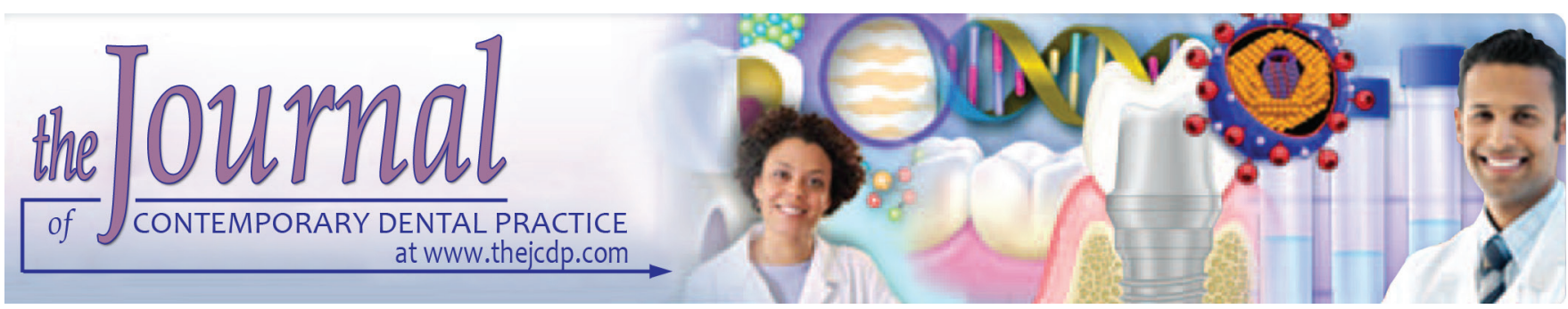

\title{
Clinical Evaluation of Microhybrid Composite and Glass Ionomer Restorative Material in Permanent Teeth
}

\author{
${ }^{1}$ Khalil Kharma, ${ }^{2}$ Tatiana Zogheib, ${ }^{3}$ Shilpa Bhandi, ${ }^{4}$ Carina Mehanna
}

\section{ABSTRACT}

Aim: The aim of this study was to clinically compare glass ionomer cement (GIC) with microhybrid composite resin used in class I cavities on permanent teeth over a period of 9 months.

Materials and methods: A total of 40 teeth with class I cavities were divided into two groups $(n=20)$ and restored with $\mathrm{GIC}$ (EQUIA; GC) and microhybrid resin composite (Amelogen Plus; Ultradent). Restorations were evaluated at $\times 4.5$ magnification using the United States Public Health Service (USPHS) criteria every 3 months. Statistical analysis was performed using the Fisher's exact test $(\alpha<0.05)$.

Results: The data obtained reported no statistical significance difference between both groups in regard to anatomical shape, color, postoperative sensitivity, secondary caries, material handling, adaptation, and marginal staining.

Conclusion: The results of this clinical study showed that GIC (EQUIA; GC) can be used for the restoration of permanent teeth and may be more appropriate for certain clinical situations than the resin composite material.

Clinical significance: EQUIA (GIC) is a viable alternative to resin composite in restoring class I cavities in permanent teeth.

Keywords: Class I, Clinical, Composite, Glass ionomer, Permanent teeth.

How to cite this article: Kharma K, Zogheib T, Bhandi S, Mehanna C. Clinical Evaluation of Microhybrid Composite and Glass Ionomer Restorative Material in Permanent Teeth. J Contemp Dent Pract 2018;19(2):226-232.

\footnotetext{
${ }^{1,4}$ Department of Restorative Dentistry, Faculty of Dental Medicine, Saint Joseph University, Beirut, Lebanon

${ }^{2}$ Department of Imaging and Pathology, Faculty of Medicine University of Leuven, Leuven, Belgium

${ }^{3}$ Department of Restorative Dentistry, College of Dentistry, Jazan University, Jazan, Kingdom of Saudi Arabia

Corresponding Author: Khalil Kharma, Department of Restorative Dentistry, Faculty of Dental Medicine, Saint Joseph University, Beirut, Lebanon, Phone: +9613242190, e-mail: khalil. kharma@gmail.com
}

\section{Source of support: Nil}

\section{Conflict of interest: None}

\section{INTRODUCTION}

The clinical applications concepts in restorative dentistry are in continuous development, to fulfill the increasing demands for esthetic restorations that are mainly achieved using resin composite. ${ }^{1}$ However, the main disadvantage of these materials is their polymerization shrinkage that leads to stress induced on the bonded surfaces and gaps formation with occasional postoperative sensitivity, especially in deep cavities. ${ }^{2}$ The clinical use of resin composite is considered to be technique-sensitive in order to achieve a long-term durable bond and a restoration free of bacterial contamination. ${ }^{3}$ The working field should be isolated and free of moisture from the oral cavity; a progressive polymerization technique to reduce shrinkage is preferred. ${ }^{4}$ Furthermore, composites are not cariostatic materials, and bonding to dentin can be unpredictable with a significant variation in the bonding efficiency. ${ }^{5-7}$

Research is still ongoing to find an ideal material for restoration, which has physical and mechanical properties similar to tooth structure and resistant to masticatory forces, while having satisfactory esthetic properties. ${ }^{8}$

Glass ionomer has been extensively explored due to several benefits they provide compared with other restorative materials. In particular, self-adhesion to tooth structure is unique among all the restorative materials. ${ }^{9,10}$

The major advantages of GIC are chemical adhesion to enamel and dentin, fluoride release, and biocompatibility. However, their low resistance to abrasion and low esthetic properties are among their main drawbacks explaining why these materials are not widely used in restorative dentistry for permanent fillings. ${ }^{11}$ 
Nowadays, the new generation of GIC ensures better esthetic results and higher and improved mechanical properties through the smaller glass particles that increase the viscosity of the material. ${ }^{12,13}$ Recently, a new GIC (EQUIA, GC Tokyo, Japan) was introduced in the market. It is made of a pure high-viscosity GIC (FUJI IX extra) coupled with a nanofilled resin varnish (EQUIA coat) that increases the resistance to abrasion of the GIC, improves marginal integrity, and leads to a satisfactory esthetic result. As reported by the manufacturer, this GIC has a coefficient of thermal expansion close to that of dentin, thereby reducing the micro-gap between the tooth and restoration, which decreases the risk of secondary caries. In addition, there is a six times more fluoride release than by the conventional GIC and the ability to fill the restoration in one shot or "bulk technique". The hardness of the GIC increases over time when in contact with saliva. ${ }^{14}$

The purpose of this study was to compare clinically a GIC (EQUIA) with a microhybrid composite (Amelogen Plus) in restoring class I cavities on permanent molars. The null hypothesis tested was that there was no difference between both materials used in restoring class I cavities.

\section{MATERIALS AND METHODS}

\section{Study Design}

A split-mouth design was followed where the central incisors received the same type of restoration. Randomization was based on the paired teeth, and it was performed using the flip of a coin for the choice of the composite material.

\section{Inclusion and Exclusion Criteria}

Between September 2013 and May 2014, a total of 15 patients aged between 25 and 63 years ( 9 females, 6 males, and mean age: 41.3 years) received 50 class I direct restorations. The patients recruited for this study were referred to the Department of Restorative Dentistry at the Faculty of Dental Medicine, Saint Joseph University, Lebanon. All patients were provided with an informed consent form approved by the ethical committee of the university's Institutional Review Board. Three patients left the study for traveling purpose; the final number of selected cavities in the study was 40 .

The inclusion criteria were subjects that were at least 18 years old, able to read and sign the informed consent form, willing to return for follow-up examinations, having no active periodontal or pulpal diseases, and having teeth with good restoration. Patients with uncontrolled parafunction or presenting unsatisfactory oral hygiene were excluded from the study.

\section{Clinical Procedures}

One skilled operator (KK) placed all the restorations. The cavities were prepared using a high-speed (Kavo, Germany) diamond bur and caries was removed using metallic burs and hand excavators. Teeth were isolated using a rubber dam to insure a moisture-free environment and avoid any contamination.

A total of 20 cavities were restored with an A3 shade microhybrid composite (Amelogen Plus, Ultradent, Utah, USA) following the manufacturer's instructions: Cavities were etched with phosphoric acid for 15 seconds (BIODINAMICA, 36\%), rinsed, and gently dried avoiding any desiccation. Then, a bonding agent (PQ1, Ultradent, Utah, USA) was applied, air thinned and light cured for 20 seconds using a light-emitting diode polymerization device that uses a growing intensity of $1200 \mathrm{~mW} / \mathrm{cm}^{2}$ (Dentamerica Litex 695 LED curing light, California, USA). The resin composite was placed in increments of 2-mm layers and light-cured for 40 seconds.

The other 20 cavities received a GIC restoration (EQUIA, GC Tokyo, Japan), following the manufacturer's instructions: Cavities were etched using the conditioner (GC cavity conditioner) for 10 seconds, then rinsed gently, and dried avoiding any desiccation. Then, the capsule was activated and material injected into the cavities using a bulk-filling technique. After condensation and setting of the material, occlusal adjustment was performed, and finally, a coating layer was applied (EQUIA coat) with a microbrush and light-cured for 20 seconds (Fig. 1).

For both materials, occlusal adjustments and polishing were done with diamond red and yellow ringed burs under irrigation, and the finishing made with silicone cups (Enhance, DENTSPLY, Pennsylvania, USA) mounted on contra-angle.

\section{Evaluation Criteria}

Two calibrated observers, who were blinded to the objective of this study, performed the evaluations. Both observers evaluated the restorations independently, according to the modified USPHS criteria (Table 1).

After data collection, in case of discrepancies in scoring, restorations were evaluated again, a consensus was reached, and this was accepted as the final score. Caries, chipping, debonding, fracture, and severe discoloration were considered as absolute failures. Restorations were evaluated at baseline, after 3, 6, and 9 months. Patients were instructed to call, upon any kind of failure. The parameters evaluated were color match, marginal discoloration, marginal adaptation, secondary caries, surface texture, anatomic contour, and postoperative sensitivity. Evaluation was performed visually and with an explorer following the modified USPHS. At each control 


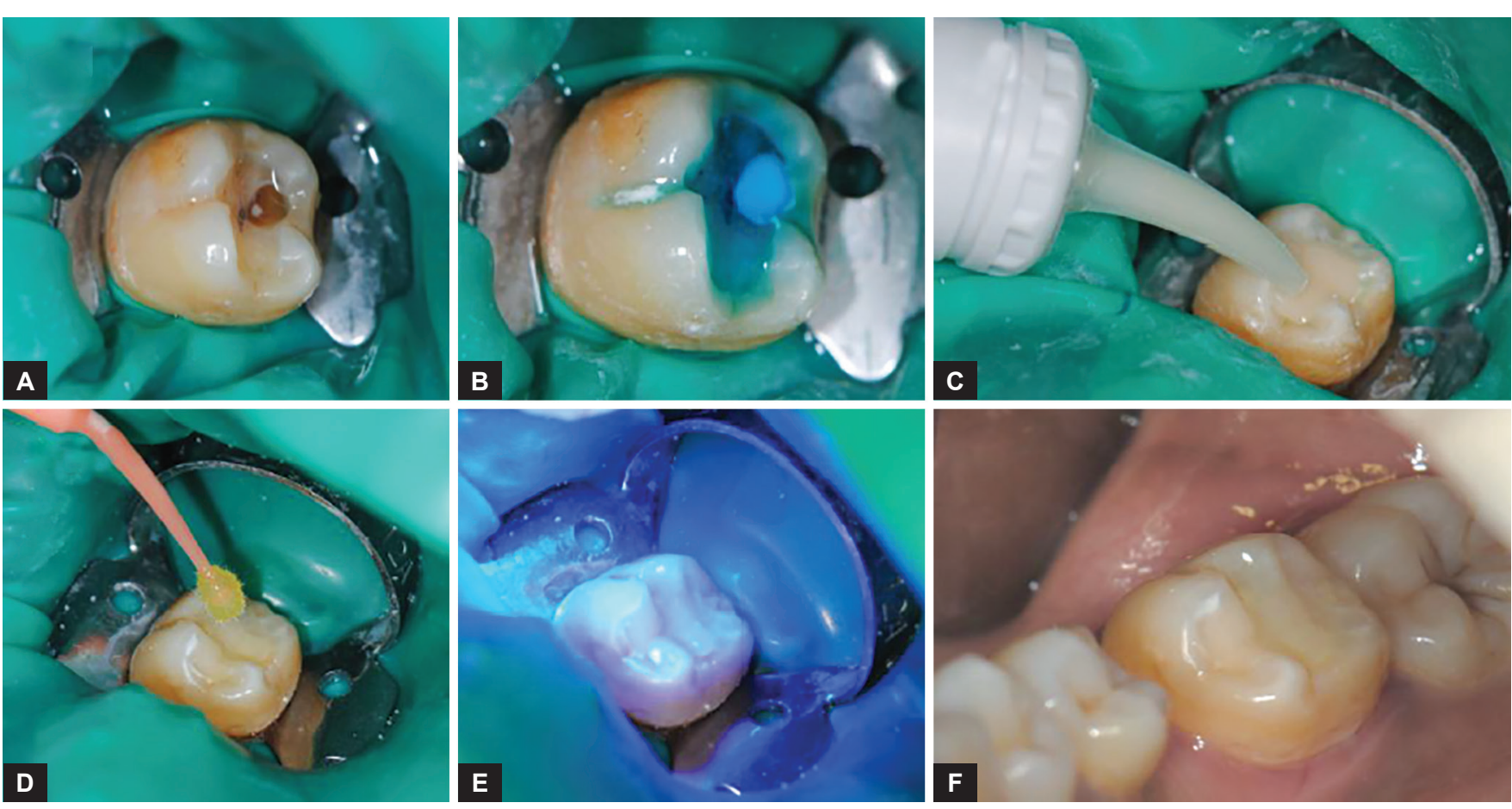

Figs 1A to F: Restoration of class I cavity with GIC (EQUIA): (A) Removal of occlusal decay; (B) application of GIC cavity conditioner for 10 seconds; (C) after activation of the material, injection in the cavity using a bulk-filling technique; (D) after occlusal adjustment and polishing, application of coating layer (EQUIA Coat); (E) light curing for 20 seconds; and (F) final restoration

Table 1: Modified USPHS criteria used

\begin{tabular}{|c|c|c|}
\hline Category & Test procedure & USPHS score: criteria \\
\hline \multirow[t]{3}{*}{ Color match } & Visual and explorer & Alfa: No mismatch to the adjacent tooth structure \\
\hline & & Bravo: Slight mismatch, but clinically acceptable \\
\hline & & Charlie: Unacceptable mismatch esthetically \\
\hline \multirow[t]{3}{*}{ Marginal discoloration } & Visual and explorer & Alpha: No discoloration on margins \\
\hline & & Bravo: Shallow discoloration \\
\hline & & Charlie: Deep discoloration \\
\hline \multirow[t]{3}{*}{ Marginal adaptation } & Visual and explorer & Alfa: Closely adapted, no visible crevice \\
\hline & & Bravo: Visible crevice, explorer will penetrate \\
\hline & & Charlie: Crevice in which dentin is exposed \\
\hline \multirow[t]{3}{*}{ Anatomic form } & Visual and explorer & Alfa: Restoration is continuous \\
\hline & & Bravo: Discontinuous, but dentin not exposed \\
\hline & & Charlie: Material missing, dentin exposed \\
\hline \multirow[t]{2}{*}{ Secondary caries } & Visual and explorer & Alfa: No caries present \\
\hline & & Charlie: Caries present \\
\hline \multirow[t]{3}{*}{ Surface texture } & Visual and explorer & Alfa: Surface as smooth as the surrounding enamel \\
\hline & & Bravo: Surface is rougher than surrounding enamel \\
\hline & & Charlie: Surface is rough avoiding continuous movement of the explorer \\
\hline \multirow[t]{3}{*}{ Postoperative sensitivity } & Visual and explorer & Alfa: Not present \\
\hline & & Bravo: Sensitive, but diminishing in intensity \\
\hline & & Charlie: Constant sensitivity not diminishing in intensity \\
\hline
\end{tabular}

visit, bite-wing radiographs were taken that helped also in evaluating marginal adaptation and secondary caries. At baseline, the shade was also recorded using an intraoral spectrophotometer (VITA EasyShade, VITA-Zahnfabrik, Germany) that helped in color evaluation. Sensitivity was assessed by tactile and air-blast tests, while the surface texture was inspected visually with a mirror and explorer for classification as enamel-like surface, rougher than enamel, and unacceptably rough.

\section{Statistical Analyses}

Data were analyzed using Statistical Software Package for the Social Sciences (version 17.0, Chicago, Illinois, USA). The significance level was set to $\mathrm{p} \leq 0.05$. 
Indicators to be measured in this study were color match, marginal discoloration, marginal adaptation, secondary caries, surface texture, anatomic contour, and postoperative sensitivity. For each of the criteria, a score of alpha was used to indicate the highest degree of clinical acceptability, and scores of Bravo, Charlie, and Delta were used to indicate progressively lessening degrees of clinical acceptability (Table 1).

Each of these indicators has been studied as a function of two factors:

1. Time: Baseline-3, 6, and 9 months (intrasubject factor).
2. Nature of the filling materials: Amelogen Plus (Ultradent, South Jordan, USA) and EQUIA (GC Tokyo, Japan).

Fisher exact tests were used to compare scores with time and between groups.

\section{RESULTS}

The results of this study are summarized in Table 2.

There was no significant difference between Amelogen and EQUIA within the clinical observations at 3, 6, and 9 months ( $p>0.05)$ for the evaluated parameters, except

Table 2: Scores of different tested parameters at baseline, 3, 6, and 9 months

\begin{tabular}{|c|c|c|c|c|c|c|}
\hline \multirow[b]{2}{*}{ Color match } & \multicolumn{2}{|c|}{ Amelogen $(n=20)$} & \multicolumn{4}{|c|}{ EQUIA $(n=20)$} \\
\hline & Alfa (\%) & Bravo (\%) & Alfa (\%) & & Bravo (\%) & \\
\hline Baseline & $20(100.0)^{a}$ & $0(0.0)^{a}$ & $20(100.0)^{a}$ & & $0(0.0)^{a}$ & \\
\hline 3 months & $20(100.0)^{a}$ & $0(0.0)^{a}$ & $20(100.0)^{a}$ & & $0(0.0)^{a}$ & \\
\hline 6 months & $20(100.0)^{a}$ & $0(0.0)^{a}$ & $20(100.0)^{a}$ & & $0(0.0)^{a}$ & \\
\hline 9 months & $20(100.0)^{a}$ & $0(0.0)^{a}$ & $20(100.0)^{a}$ & & $0(0.0)^{a}$ & \\
\hline \multicolumn{7}{|l|}{ Secondary caries } \\
\hline Baseline & $20(100.0)^{a}$ & $0(0.0)^{a}$ & $20(100.0)^{a}$ & & $0(0.0)^{a}$ & \\
\hline 3 months & $20(100.0)^{a}$ & $0(0.0)^{a}$ & $20(100.0)^{a}$ & & $0(0.0)^{a}$ & \\
\hline 6 months & $20(100.0)^{a}$ & $0(0.0)^{a}$ & $20(100.0)^{a}$ & & $0(0.0)^{a}$ & \\
\hline 9 months & $20(100.0)^{a}$ & $0(0.0)^{a}$ & $20(100.0)^{a}$ & & $0(0.0)^{a}$ & \\
\hline \multicolumn{7}{|c|}{ Postoperative sensitivity } \\
\hline Baseline & $20(100.0)^{a}$ & $0(0.0)^{a}$ & $20(100.0)^{a}$ & & $0(0.0 \%)^{a}$ & \\
\hline 3 months & $18(90.0)^{a}$ & $2(10.0)^{a}$ & $20(100.0)^{a}$ & & $0(0.0 \%)^{\mathrm{a}}$ & \\
\hline 6 months & $18(90.0)^{a}$ & $2(10.0)^{a}$ & $20(100.0)^{a}$ & & $0(0.0 \%)^{\mathrm{a}}$ & \\
\hline 9 months & $18(90.0)^{a}$ & $2(10.0)^{a}$ & $20(100.0)^{a}$ & & $0(0.0 \%)^{\mathrm{a}}$ & \\
\hline \multicolumn{7}{|l|}{ Surface texture } \\
\hline Baseline & $20(100.0)^{a}$ & $0(0.0)^{a}$ & $20(100.0)^{a}$ & & $0(0.0)^{a}$ & \\
\hline 3 months & $20(100.0)^{a}$ & $0(0.0)^{a}$ & $19(95.0)^{a}$ & & $1(5.0)^{a}$ & \\
\hline 6 months & $18(90.0)^{a}$ & $2(10.0)^{a}$ & $14(70.0)^{b}$ & & $6(30.0)^{b}$ & \\
\hline 9 months & $18(90.0)^{a}$ & $2(10.0)^{a}$ & $14(70.0)^{b}$ & & $6(30.0)^{b}$ & \\
\hline \multicolumn{7}{|l|}{ Anatomic contour } \\
\hline Baseline & $20(100.0)^{a}$ & $0(0.0)^{a}$ & $20(100.0)^{\mathrm{a}}$ & & $0(0.0)^{a}$ & \\
\hline 3 months & $20(100.0)^{a}$ & $0(0.0)^{a}$ & $19(95.0)^{a}$ & & $1(5.0)^{a}$ & \\
\hline 6 months & $18(90.0)^{a}$ & $2(10.0)^{a}$ & $14(70.0)^{b}$ & & $6(30.0)^{b}$ & \\
\hline \multirow[t]{2}{*}{9 months } & $18(90.0)^{\mathrm{a}}$ & $2(10.0)^{a}$ & $14(70.0)^{\mathrm{b}}$ & & $6(30.0)^{\mathrm{b}}$ & \\
\hline & \multicolumn{3}{|c|}{ Amelogen $(n=20)$} & \multicolumn{3}{|c|}{ EQUIA $(n=20)$} \\
\hline Marginal adaptation & Alfa (\%) & Bravo (\%) & Charlie (\%) & Alfa (\%) & Bravo (\%) & Charlie (\%) \\
\hline Baseline & $20(100.0)^{a}$ & $0(0.0)^{a}$ & $0(0.0)^{a}$ & $20(100.0)^{a}$ & $0(0.0)^{a}$ & $0(0.0)^{a}$ \\
\hline 3 months & $20(100.0)^{a}$ & $0(0.0)^{a}$ & $0(0.0)^{a}$ & $20(100.0)^{a}$ & $0(0.0)^{a}$ & $0(0.0)^{a}$ \\
\hline 6 months & $20(100.0)^{a}$ & $0(0.0)^{a}$ & $0(0.0)^{a}$ & $20(100.0)^{a}$ & $0(0.0)^{a}$ & $0(0.0)^{a}$ \\
\hline 9 months & $20(100.0)^{a}$ & $0(0.0)^{a}$ & $0(0.0)^{a}$ & $20(100.0)^{a}$ & $0(0.0)^{a}$ & $0(0.0)^{a}$ \\
\hline \multicolumn{7}{|l|}{ Marginal adaptation } \\
\hline Baseline & $20(100.0)^{a}$ & $0(0.0)^{a}$ & $0(0.0)^{a}$ & $20(100.0)^{a}$ & $0(0.0)^{a}$ & $0(0.0)^{a}$ \\
\hline 3 months & $20(100.0)^{a}$ & $0(0.0)^{a}$ & $0(0.0)^{a}$ & $20(100.0)^{a}$ & $0(0.0)^{a}$ & $0(0.0)^{a}$ \\
\hline 6 months & $20(100.0)^{a}$ & $0(0.0)^{a}$ & $0(0.0)^{a}$ & $20(100.0)^{a}$ & $0(0.0)^{a}$ & $0(0.0)^{a}$ \\
\hline 9 months & $20(100.0)^{a}$ & $0(0.0)^{a}$ & $0(0.0)^{a}$ & $20(100.0)^{a}$ & $0(0.0)^{a}$ & $0(0.0)^{a}$ \\
\hline \multicolumn{7}{|l|}{ Marginal discoloration } \\
\hline Baseline & $20(100.0)^{a}$ & $0(0.0)^{a}$ & $0(0.0)^{\mathrm{a}}$ & $20(100.0)^{\mathrm{a}}$ & $0(0.0)^{a}$ & $0(0.0)^{a}$ \\
\hline 3 months & $20(100.0)^{a}$ & $0(0.0)^{a}$ & $0(0.0)^{a}$ & $20(100.0)^{a}$ & $0(0.0)^{a}$ & $0(0.0)^{a}$ \\
\hline 6 months & $20(100.0)^{a}$ & $0(0.0)^{a}$ & $0(0.0)^{a}$ & $20(100.0)^{a}$ & $0(0.0)^{a}$ & $0(0.0)^{a}$ \\
\hline 9 months & $20(100.0)^{a}$ & $0(0.0)^{\mathrm{a}}$ & $0(0.0)^{a}$ & $20(100.0)^{a}$ & $0(0.0)^{a}$ & $0(0.0)^{a}$ \\
\hline
\end{tabular}

Similar superscripts indicate no statistical significance $(p<0.05)$ 
for surface texture that decreased significantly over time for the cavities restored with EQUIA $(p<0.05)$.

\section{DISCUSSION}

The results of this study led to the acceptance of the null hypotheses that there was no significant difference between tested materials except for the surface texture of teeth restored with EQUIA, which showed rougher surface when compared with baseline. The GIC restorations have several advantages when compared with other restorative materials, mainly, the release of fluoride, chemical adhesion to dental structures, as well as an acceptable moisture tolerance. Clinical studies in class $\mathrm{V}$ cavities showed very promising results following the filling with GIC. ${ }^{15,16}$ The poor mechanical properties of conventional GIC compared with resin composite make them unlikely to be used in the posterior regions. ${ }^{12}$ Significant efforts have been made to enhance the strength and mechanical properties of GIC as a GC company introduced EQUIA with improved properties to be used as an alternative to resin composite and amalgam in permanent teeth.

The results of the present study reported no significant differences in shade matching, postoperative sensitivity, material handling, secondary caries, and marginal staining between GC (EQUIA) and the resin composite (Amelogen Plus, Ultradent) used for class I cavities in permanent teeth; this is in accordance with a recent published study by Gurgan et al ${ }^{17}$ that evaluated the clinical performance over 6 years of GIC systems, concluding an acceptable behavior of EQUIA over time. Another clinical report showed that the EQUIA system, based on a high-viscosity resin-coated GIC cement, seems to be a reliable choice for long-term dental restorations, even in load-bearing teeth surfaces. ${ }^{18}$

In our study, no significant difference was found in the anatomical shape of the material. All restorations were intact after 9 months and no fracture or loss of material was reported; this may be due to the improved mechanical properties of the high-viscosity tested GIC. The compressive strength of the GIC increases with time from 136 to $236 \mathrm{MPa}$ after 24 hours. ${ }^{19}$ Another study ${ }^{20}$ showed a survival rate of $93 \%$ for $3 \frac{1}{2}$ years and $60 \%$ over 6 years in class II, which is not optimal, but is within the level of success of composite restorations. ${ }^{21}$ A study by Scholtanus and Huysmans ${ }^{21}$ showed that adding a nanocharged resin on the surface of GIC improves its mechanical properties significantly. All these studies confirmed the results reported in this study.

Regarding the surface texture, there was a significant difference between "EQUIA" and "Amelogen Plus." Six cavities restored with GIC received a Bravo score, meaning that the surface was rougher than enamel, but still clinically acceptable; this may be due to the loss of the nanocharged resin layer that was applied on the surface of the restoration to protect the GIC until complete setting.

This is in accordance with other published reports stating that the nanocharged resin layer applied to the surface of the GIC will improve its abrasion resistance significantly. ${ }^{22}$ The results of the present study showed that EQUIA performed similarly to resin composite that is in accordance with other studies ${ }^{23,24}$ reporting that highviscosity GIC can be used as permanent restoration with satisfactory results over 2 years. Long-term resistance to abrasion of high-viscosity GIC can be achieved as long as early wear characteristics are improved and no premature loss of the protective resin layer occurred due to several factors such as aggressive brushing or bruxism. ${ }^{25}$

Marginal adaptation reported no difference between the tested materials that may be explained by the presence of a resin layer securing a protective barrier, which isolates the restoration from all external contamination. According to the study by Lohbauer et al, ${ }^{26}$ the resin layer ensures the sealing of the restoration and protection from any porosities and cracks; in addition, the GIC chemically adheres to dental structures unlike composites that require an adhesive.

The GIC is delivered in capsules with an ideal powder/liquid ratio as instructed by the manufacturer. Hence, for daily clinical use, it is best to use premeasured capsules. Otherwise, it would be difficult to reach a perfect powder/liquid ratio, which would affect the mechanical properties of GIC cements. ${ }^{27}$ Worthy of mention is that the GIC has a slight advantage over composites in that it is considered as technique-sensitive, where filling should be done by layers not exceeding $2 \mathrm{~mm}$ in isolated, moisturefree operating environment. This is difficult to achieve in elderly patients and noncooperative children with high caries risk or when the rubber dam is impossible to install. ${ }^{28}$ The GIC can be a satisfactory alternative therapy in these cases with a superior outcome compared with composites, especially with the release of fluoride, which is an important factor in the prevention against secondary caries. "EQUIA" is considered as less techniquesensitive than resin composite; it is moisture-tolerant and allows a bulk filling technique since it does not undergo volumetric shrinkage during polymerization, unlike composites. ${ }^{30}$ Thus, it provides a significant gain of clinical time. The GIC has a working time of $<1$ minute 15 seconds after activation of the capsule, which makes shaping the occlusal surface of the restoration rather difficult. Usually, the use of a handpiece is needed. ${ }^{27}$

Two cases of postoperative sensitivity were reported with the resin composite restorations that may be due to polymerization shrinkage, resulting in high stress due to 
the configuration factor of the class I cavity responsible for the formation of microhiatus. ${ }^{2}$

The composites currently used in the market have a volume contraction rate between 2.58 and $3.08 \%$. According to the manufacturer, the Amelogen Plus (Ultradent) composite has a rate of polymerization shrinkage of around 3\%. The volume of the cured resin in composite, its composition, and the degree of conversion control the contraction. ${ }^{30}$

Clinical studies are difficult to conduct due to the high rate of "dropout" reducing the sample size and the difficulty to standardize the type, size, and depth of the restored cavity. ${ }^{20}$ However, they are more reliable than in vitro studies as the material tested is subjected to the oral environment that is difficult to replicate in vitro. Resin composite is considered as the material of choice for class I and II posterior restorations. These materials have a major drawback due to the polymerization shrinkage and stress induced that can lead to cracks, postoperative sensitivity, and failure of the restoration. ${ }^{31}$

Future long-term prospective studies should be conducted to validate the results of the present study and evaluate the behavior of GIC over time.

\section{CONCLUSION}

Within the limitations of this study, EQUIA is a viable alternative to resin composite in restoring class I cavities in permanent teeth, adding the advantages of adhesion, fluoride release, and bulk-fill technique.

\section{ACKNOWLEDGMENT}

The authors would like to thank Professor Ziad Salameh for his precious help in editing this manuscript.

\section{REFERENCES}

1. Schwendicke F, Göstemeyer G, Blunck U, Paris S, Hsu LY, $\mathrm{Tu}$ YK. Directly placed restorative materials: review and network meta-analysis. J Dent Res 2016 Jun;95(6):613-622.

2. Alomari Q, Ajlouni R, Omar R. Managing the polymerization shrinkage of resin composite restorations: A review. SADJ 2007 Feb;62(1):12, 14, 16 passim.

3. Glauser S, Astasov-Frauenhoffer M, Müller JA, Fischer J, Waltimo T, Rohr N. Bacterial colonization of resin composite cements: influence of material composition and surface roughness. Eur J Oral Sci 2017 Aug;125(4):294-302.

4. Liu Y, Tjäderhane L, Breschi L, Mazzoni A, Li N, Mao J, Pashley DH, Tay FR. Limitations in bonding to dentin and experimental strategies to prevent bond degradation. J Dent Res 2011 Aug;90(8):953-968.

5. El Gezawi M, Haridy R, Elazm EA, Al-Harbi F, Zouch M, Kaisarly D. Microtensile bond strength, 4-point bending and nan leakage of resin-dentin interfaces: effects of two matrix metalloproteinase inhibitors. J Mech Behav Biomed Mater 2017 Nov;78:206-213.
6. Matos AB, Trevelin LT, Silva BTFD, Francisconi-Dos-Rios LF, Siriani LK, Cardoso MV. Bonding efficiency and durability: current possibilities. Braz Oral Res 2017 Aug;31(Suppl 1):e57.

7. Rodrigues RV, Giannini M, Pascon FM, Panwar P, Brömme D, Manso AP, Carvalho RM. Effect of conditioning solutions containing ferric chloride on dentin bond strength and collagen degradation. Dent Mater 2017 Oct;33(10):1093-1102.

8. Barreto Bde C, Van Meerbeek B, Van Ende A, Sousa SJ, Silva GR, Soares PV, Soares CJ. Biomechanical behavior of extensively restored premolars: cusp deformation, marginal integrity, and fracture resistance. J Adhes Dent 2015 Jun;17(3):213-218.

9. Duque C, Aida KL, Pereira JA, Teixeira GS, Caldo-Teixeira AS, Perrone LR, Caiaffa KS, Negrini TC, Castilho AR, Costa CA. In vitro and in vivo evaluations of glass-ionomer cement containing chlorhexidine for atraumatic restorative treatment. J Appl Oral Sci 2017 Sep-Oct;25(5):541-550.

10. Kielbassa AM, Glockner G, Wolgin M, Glockner K. Systematic review on highly viscous glass-ionomer cement/resin coating restorations (Part I): do they merge Minamata convention and minimum intervention dentistry? Quintessence Int 2016 Nov-Dec;47(10):813-823.

11. Mount GJ, Tyas MJ, Ferracane JL, Nicholson JW, Berg JH, Simonsen RJ, Ngo HC. A revised classification for direct tooth-colored restorative materials. Quintessence Int 2009 Sep;40(8):691-697.

12. Condò R, Cerroni L, Pasquantonio G, Mancini M, Pecora A, Convertino A, Mussi V, Rinaldi A, Maiolo L. A deep morphological characterization and comparison of different dental restorative materials. BioMed Res Int 2017 Jun;2017: 7346317.

13. Zoergiebel J, Ilie N. Evaluation of a conventional glass ionomer cement with new zinc formulation: effect of coating, aging and storage agents. Clin Oral Investig 2013 Mar;17(2):619-626.

14. Sadaghiani L, Adusei G, Rees J. Effects of storage media on physical properties of selected tooth coloured restorative materials. Eur J Prosthodont Restor Dent 2009 Sep;17(3): 116-120.

15. de Souza EM, Cefaly DF, Terada RS, Rodrigues CC, de Lima Navarro MF. Clinical evaluation of the ART technique using high density and resin-modified glass ionomer cements. Oral Health Prev Dent 2003;1(3):201-207.

16. Tyas MJ. Cariostatic effect of GIC: a five-year clinical study. Aust Dent J 1991 Jun;36(3):236-239.

17. Gurgan S, Kutuk ZB, Ergin E, Oztas SS, Cakir FY. Clinical performance of a glass ionomer restorative system: A 6-year evaluation. Clin Oral Investig 2017 Sep;21(7):2335-2343.

18. Basso, M. Long-term dental restorations using high-viscosity coated glass ionomer cements. The Preliminary Program for IADR/AADR/CADR. San Francisco (CA): 89th General Session and Exhibition; 2011. pp. 16-19.

19. Peez R, Frank S. The physical-mechanical performance of the new ketac molar easymix compared to commercially available glass ionomer restoratives. J Dent 2006 Sep;34(8):582-587.

20. Friedl K, Hiller KA, Friedl KH. Clinical performance of a new glass ionomer based restoration system: a retrospective cohort study. Dent Mater 2011 Oct;27(10):1031-1037.

21. Scholtanus JD, Huysmans MC. Clinical failure of class-II restorations of a highly viscous glass-ionomer material over a 6-year period: a retrospective study. J Dent 2007 Feb;35(2): 156-162. 
22. Bonifacio, CA.; van Amerongen, WE.; Werner, A.; Kleverlaan, C. The effect of coating glass ionomers with a nanofilled resin. Barcelona: Abstract 2987-IADR; 2010.

23. Gurgan S, Kutuk ZB, Ergin E, Oztas SS, Cakir FY. Four-year randomized clinical trial to evaluate the clinical performance of a glass ionomer restorative system. Oper Dent 2015 Mar-Apr; 40(2):134-143.

24. Burke FJ, Siddons C, Cripps S, Bardha J, Crisp RJ, Dopheide B.Clinical performance of reinforced glass ionomer restorations placed in UK dental practices. Br Dent J 2007 Jul;203(1):E2.

25. van Duinen RN, Kleverlaan CJ, de Gee AJ, Werner A, Feilzer AJ. Early and long-term wear of 'fast-set' conventional glass-ionomer cements. Dent Mater 2005 Aug;21(8): 716-720.

26. Lohbauer U, Krämer N, Siedschlag G, Schubert EW, Lauerer B, Müller FA, Petschelt A, Ebert J. Strength and wear resistance of a dental glass-ionomer cement with a novel nanofilled resin coating. Am J Dent 2011 Apr;24(2):124-128.
27. Dowling AH, Fleming GJ. Is encapsulation of posterior glassionomer restoratives the solution to clinically induced variability introduced on mixing? Dent Mater 2008 Jul;24(7):957-966.

28. Hahnel S, Ionescu AC, Cazzaniga G, Ottobelli M, Brambilla E. Biofilm formation and release of fluoride from dental restorative materials in relation to their surface properties. J Dent 2017 May;60:14-24.

29. Bayrak GD, Sandalli N, Selvi-Kuvvetli S, Topcuoglu N, Kulekci G. Effect of two different polishing systems on fluoride release, surface roughness and bacterial adhesion of newly developed restorative materials. J Esthet Restor Dent 2017 Nov;15(6):297-304.

30. Gaintantzopoulou MD, Gopinath VK, Zinelis S. Evaluation of cavity wall adaptation of bulk esthetic materials to restore class II cavities in primary molars. Clin Oral Investig 2017 May;21(4):1063-1070.

31. Al-Boni R, Raja OM. Microleakage evaluation of silorane based composite versus methacrylate based composite. J Conserv Dent 2010 Jul;13(3):152-155. 